\title{
Firmness, Respiration, and Weight Loss of 'Bing', 'Lapins' and 'Sweetheart' Cherries in Relation to Fruit Maturity and Susceptibility to Surface Pitting
}

\author{
Peter M.A. Toivonen, ${ }^{1}$ Frank Kappel, Sabina Stan, \\ Darrell-Lee McKenzie, and Rod Hocking \\ Agriculture and Agri-Food Canada, Pacific Agri-Food Research Centre, \\ Summerland, British Columbia, Canada VOH $1 Z 0$
}

Additional index words. Prunus avium, weight loss, respiration, firmness, predictive modeling

\begin{abstract}
A convenient and reliable method that used a specially designed tool to apply a uniform bruising force in situ was developed to assess the relative susceptibility to fruit surface pitting in sweet cherry. Assessment of pitting with a visual scale after 2 weeks of 1 ${ }^{\circ} \mathrm{C}$ storage was found to be in close agreement with measurements of pit diameter. Using this method 'Bing' showed the greatest susceptibility to pitting in both years of the study and 'Bing', 'Lapins', and 'Sweetheart' cherries showed a decline in susceptibility as fruit matured. The predictive value of fruit firmness at harvest, fruit respiration at harvest, and weight loss in storage was assessed in relation to the severity of pitting. The model to best describe pitting was found to include all three physiological variables (firmness, respiration, and weight loss). While an acceptable model was obtained when combining all three cultivars, the best models were achieved when each cultivar was considered separately. It was concluded that there are likely unmeasured variables involved in determining susceptibility to pitting. Hence the best approach to predicting pitting susceptibility is the application of the pit-induction method described in this work.
\end{abstract}

Surface pitting is a serious post-harvest quality problem in sweet cherries (Porritt et al., 1971), with some cultivars showing greater susceptibility than others. The pitting symptom appears some days or even weeks after bruising. Previous work has shown that fruit are more susceptible to injury leading to pitting if handled at lower temperatures (Lidster and Tung, 1980) and Patten et al. (1983) recommended that fruit be sorted prior to cooling, since much of the injury occurs during movement on the sorting line and at the cluster cutting stage in the line.

Previous work in simulating pitting involved dropping fruit a known distance onto a dimpled belt, similar to the belts used in cherry packing lines at the time (Crisosto et al., 1994; Kupferman et al., 1995). However, that treatment can result in bias due to fruit weight; i.e., heavier fruit dropped a given distance will be exposed to greater forces than lighter fruit. In addition, the number of pits potentially generated was not always uniform and depended on how the fruit landed on the belt during the drop (personal observation). Therefore, before consistent pitting evaluations could be made, an improved procedure to induce pitting was required.

Received for publication 20 May 2003. Accepted for publication 9 Sept. 2003. Contribution 2208 of the Pacific Agri-Food Research Centre. The authors would like to thank Michael Weis for his expert assistance with microscopy and image analysis and Gordon Houston, DDS, for advice and samples of dental impression compounds.

${ }^{1}$ To whom requests for reprints should be addressed; e-mail toivonenp@agr.gc.ca.
While pitting susceptibility is influenced by maturity in 'Van' (Lidster et al., 1980) and 'Lambert' (Couey and Wright, 1974), there has been no examination of this relationship with either 'Bing' or any of the newer cultivars of sweet cherry now widely planted in North America. Firmness has been implicated as being an important factor in the determination of pitting susceptibility (Facteau, 1982; Facteau and Rowe, 1979; Looney and Lidster, 1980). Firmness is also an indicator of cell wall structure and is considered to be important in describing tissue response to mechanical forces (Facteau, 1982). Therefore, firmness was considered to be a physiological factor with potential to be a good predictor of pitting susceptibility.

While much has been done to evaluate the potential influences of cell wall structure on pitting susceptibility, questions have arisen as to whether there are other factors that might influence severity of pitting (Blachovec and Pato_ka, 1996; Choi et al., 2002a). Therefore, it was decided that other physiological characteristics should be examined. Water loss has been implicated as an important factor in the development of pits after mechanical injuries have been incurred (Toivonen, unpublished data; Lidster and Tung, 1980). Cultivar and/or maturity differences in susceptibility to pitting injury could potentially be influenced by water loss potential. Respiratory activity (or metabolic rate) might be expected to show some relation to pit development since glycolysis and respiration are important processes required for production of ATP and intermediates required in numerous biosynthetic pathways (Plaxton,
1996) and may hence be important in repairing the mechanical injury that leads to pitting.

The first goal of this work was to develop a rapid and reliable method to artificially induce pitting and to confirm that visual ratings could be used in place of actual measurement of pits. The second goal was to evaluate relative susceptibility to surface pitting of three important cultivars in two growing seasons and at different maturities. Finally, we have attempted to relate differences in pitting susceptibility to three physiological measures: fruit firmness at harvest, fruit respiration at harvest, and water loss during storage.

\section{Materials and Methods}

Fruit selection. All three cultivars were harvested on different dates at color stages 2 to 7 , using Centre technique interprofessionel de fruits et légumes (CTIFL, Paris) color comparators for surface color of sweet cherries. Information on this comparator (Code Couleur Cerise) can be accessed at the web site http://www.ctifl.fr/Publication/publications.htm. Color stage 2 is light red and color stage 7 is dark mahogany. Optimal harvest color is considered to be between 5 and 6 but commercial harvest often occurs as early as a color rating of 4 . In the case of 'Sweetheart' it is difficult to reach color stage 7 before the fruit begin to shrivel and decay at Summerland, B.C., in most years, therefore fruit were not harvested at stage 7 for that cultivar. The cherries were harvested in the morning and brought to the laboratory within an hour of harvest. The fruit were inspected and culls (split, diseased or damaged fruit) were discarded. The remaining

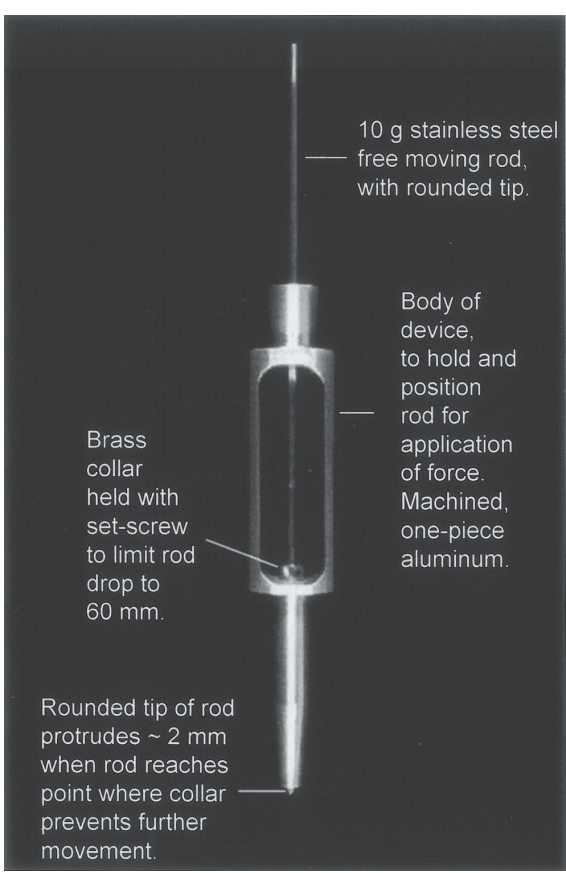

Fig. 1. Photograph of device designed to induce a controlled, repeatable bruising force to individual cherry fruit. The bottom tip of the device is carefully placed on the surface of the cherry and the rod is lifted to the highest level which the collar will allow and is simply let go to induce the injury on the surface of the fruit. 


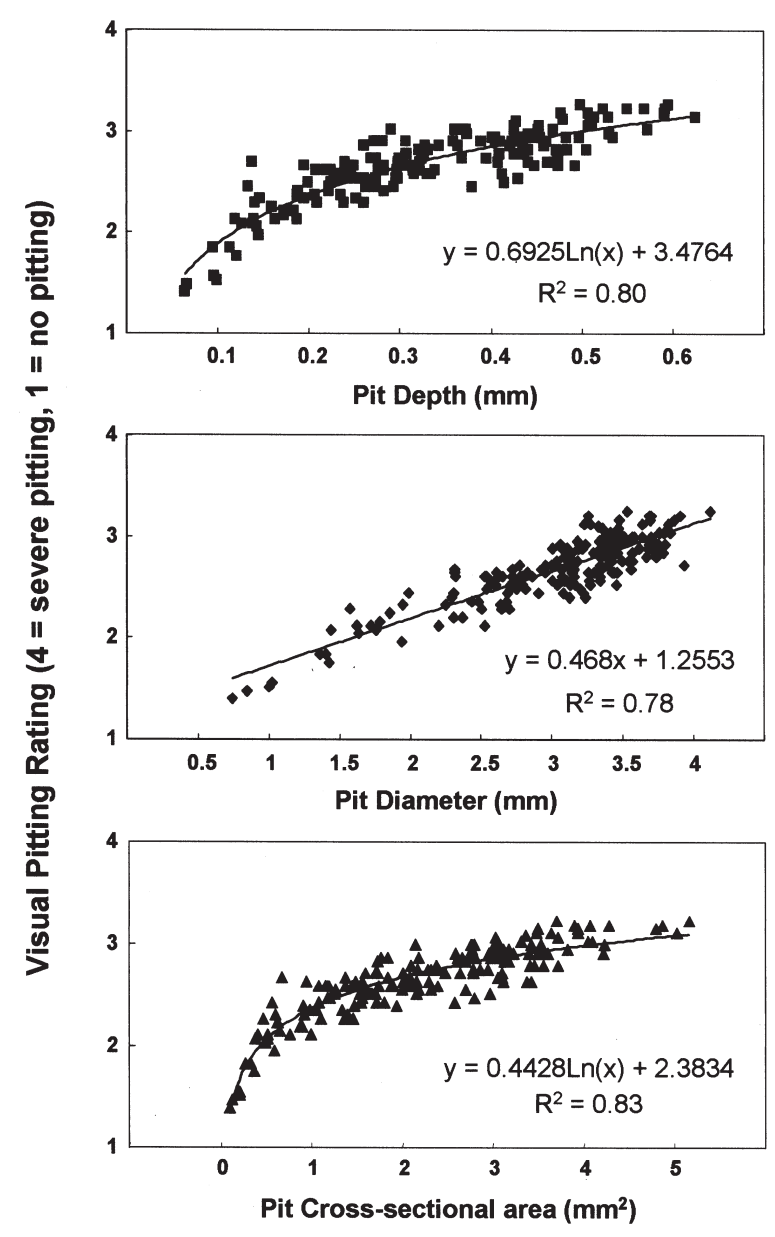

Fig. 2. Regression of three measures of surface pits against a visual pitting rating. Note pit crosssectional area was calculated from pit diameter and depth assuming a triangular pit. The visual rating scale was as follows: $1=$ no pitting; $2=$ superficial pitting, i.e., very shallow depression in the skin with edges being diffuse; $3=$ moderate pitting, i.e., the pit was deeper and wider and had clearly distinct edges; 4 = severe pitting, i.e., the pits were very deep and edges of the pit had sunken into the pulp tissue.

fruit of each cultivar were randomly placed into clear polystyrene clamshell containers [1.5 dry pint $(775 \mathrm{~mL})$; Berigard Hinged Basket, Packaging Corporation of America, Northbrook, Ill,]. Each clamshell contained 25 fruit. Once the clamshells were filled, they were placed into a $4{ }^{\circ} \mathrm{C}$ room.

A 25-fruit sample of fruit not placed into the clamshells was assessed for firmness using a pressure tester (FirmTech 1; BioWorks, Stillwater, Okla.). Firmness was determined at harvest for all three cultivars at all maturity stages.

The induction of pitting involved fruit held at $4{ }^{\circ} \mathrm{C}$ for $4 \mathrm{~h}$ and used a device specifically designed for this purpose (Fig. 1). A force known to induce pitting was applied by dropping a 10-g stainless-steel rod of $2.5 \mathrm{~mm}$ in diameter from a $60-\mathrm{mm}$ height onto the surface of the fruit. During the application of the bruising force each fruit was sitting in one of twenty-five 2.5-cm-diameter rounded wells which had been machined into a short length of spruce $2 \times 4$-inch lumber. After the pitting induction treatment, these fruit were returned to the polystyrene clamshell containers and held at $1{ }^{\circ} \mathrm{C}$ for 2 weeks. To assess water loss, five replications, each consisting of 25 fruit, were weighed at harvest and again after 2 weeks of storage.

The pits were evaluated after 2 weeks, using both a visual rating and also a dental impression compound to produce an exact negative that could be measured under a microscope. The visual rating used the following scale: $1=$ no pitting; 2 = superficial pitting, i.e., very shallow depression in the skin with edges being diffuse; $3=$ medium pitting, i.e., the pit was deeper and wider and had clearly distinct edges; $4=$ severe pitting, i.e., the pit was very deep and edges of the pit had sunken into the pulp tissue. The impressions of the pits were taken after storage, using Type 1 (low viscosity) Aquasil LV Smart Wetting Impression Material (Dentsply International Inc., Milford, Del.), which was applied with the Dentsply MixPac caulk dispenser. This two part dental impression compound was found to produce stable, detailed negative replicas of the pit area. Once cured $(\approx 5 \mathrm{~min})$ the pit impressions were stored in sealed $25-\mathrm{mL}$ glass vials at room temperature after flushing the vials with $\mathrm{N}^{2}$. This was done as a precaution to ensure that the impression dimensions remained stable until they could be measured. A 0.5-mm-thick cross-sectional slice was cut from the negative impression of each pit using a sharp razor blade. The pit diameter and depth were directly measured using a dissecting microscope (model M8; Wild Leitz Canada Ltd., Willowdale, Ont.) fitted with a digital video camera (Panasonic WV-D5000; Matsushita Commercial Industries Co.,Ltd., Japan). Dimension measurement was accomplished with a video imaging program (Image Pro-Plus, version 3.0 for Windows, Media Cybernetics, Silver Spring, Md.), after calibration with a known standard rule. Assuming the pit area was triangular in shape, pit cross-sectional areas were calculated using the height and width measurements taken with the digital imaging system.

Respiration was measured as reported previously (Kappel etal., 2002). At harvest, fruit samples (15 to $30 \mathrm{~g}$ ) were placed in 1-L plastic jars with tight-fitting lids and put into a $20{ }^{\circ} \mathrm{C}$ incubator (model 307; Fisher Scientific Canada, Nepean, Ont.). Jars were continuously flushed with air at a rate of 1.5 $\mathrm{L} \cdot \mathrm{h}^{-1}$. The output of each jar was connected to an automated solenoid switching system. Every $5 \mathrm{~min}$ the sampler was advanced to the output from the next jar and the $\mathrm{CO}_{2}$ detector was flushed with gas from a new sample. The level of $\mathrm{CO}_{2}$ was detected with a $\mathrm{P}$ infrared instrument(Type DPIP-CD-1900-0; Analytical Development Co., Hoddesdon, England) and logged by computer. Samples were analyzed over a 24-h period. Rates of $\mathrm{CO}_{2}$ production are expressed as $\mathrm{mL} \mathrm{CO}_{2} / \mathrm{kg} / \mathrm{h}$.

All statistical analyses were performed using SAS software (SAS, Cary, N.C.). The relationship of visual pitting ratings to pit diameter, depth and calculated cross-sectional pit area was evaluated by regression analysis. All physiological parameter and pitting data were analyzed in a factorial design with cultivar, maturity, and year as main effects. Maturity level 7 was never achieved in 'Sweetheart', therefore those values for that cultivar were treated as missing data. For all measures, the three way interactions were found to be significant, so data are presented as graphs of simple effects with standard errors for each data point. The relationship of respiration at harvest, firmness at harvest and weight loss during storage to level of pitting was evaluated by regression analysis.

\section{Results and Discussion}

There was a strong linear correlation between visual pitting ratings and the measured

Fig. 3. Changes in pitting susceptibility of three sweet cherry cultivars with advancing maturity as determined using a CTIFL color (Centre technique interprofessionel de fruits et légumes, Paris) comparator to evaluate fruit external color. Pitting was induced by applying point force at $4{ }^{\circ} \mathrm{C}$. Note: Pitting scale is same as described in Fig. 2. Vertical lines, when visible, represent standard errors of the means.

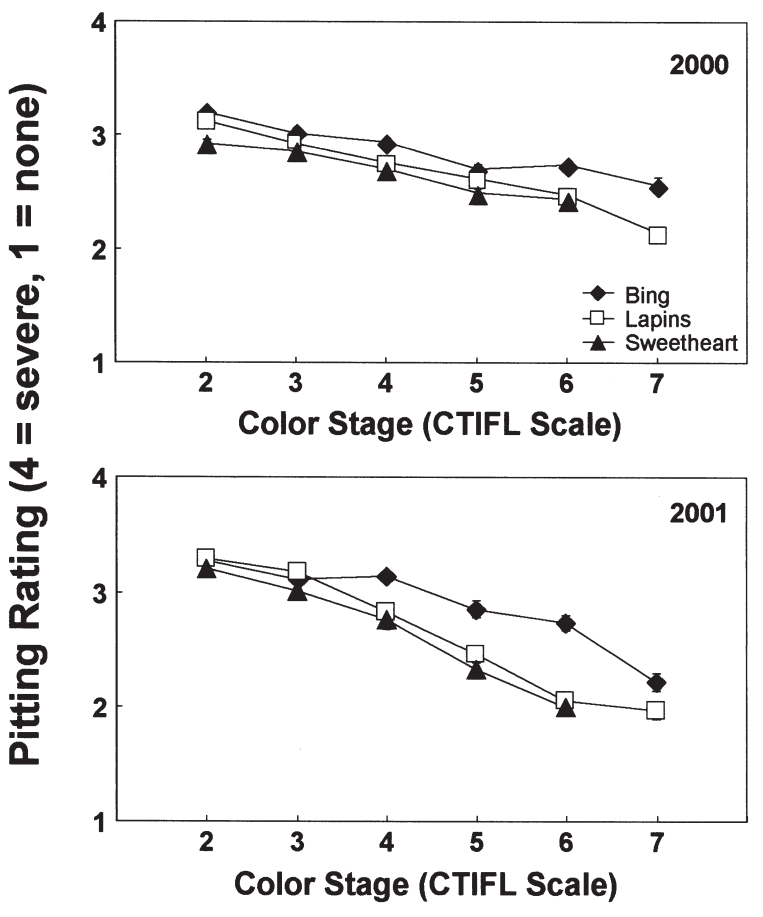



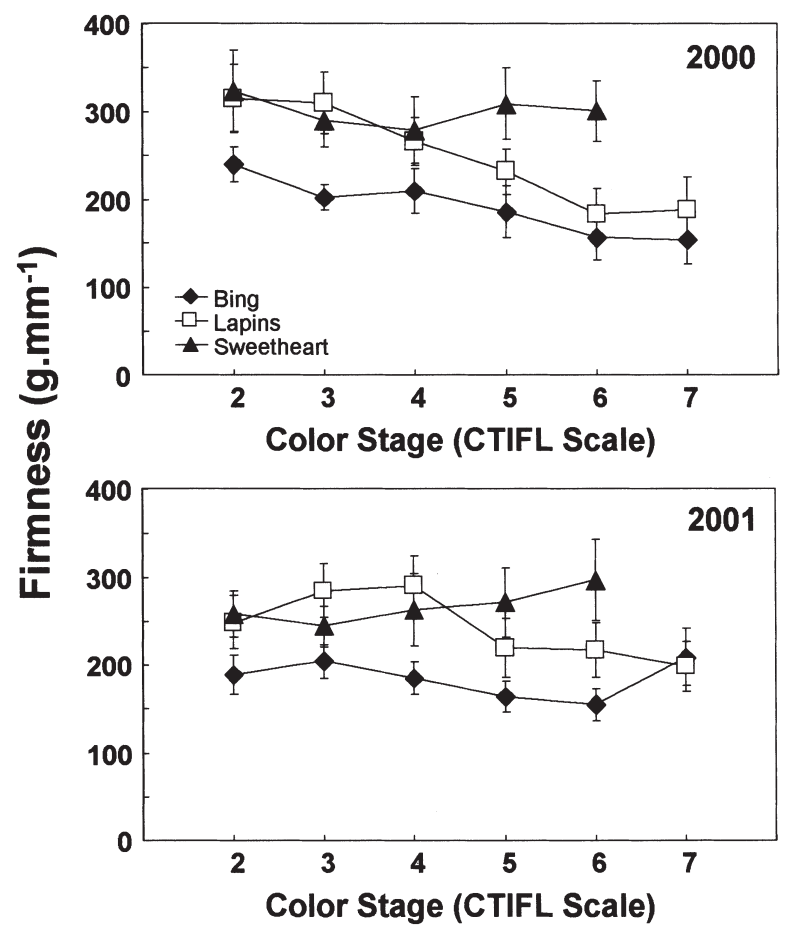

Fig. 4. Changes in firmness of three sweet cherry cultivars with advancing maturity as determined using a CTIFL color (Centre technique interprofessionel de fruits et légumes, Paris) comparator to evaluate fruit external color. Vertical lines, when visible, represent standard errors of the means.

diameter of the pit (Fig. 2). The correlation of ratings to pit depth and calculated cross-sectional area was quite strong, except the relationship was not linear. These results indicate that visual rating gives a good representation of pit diameter throughout the range of pit sizes which were induced in this work. The deviation from linearity in the relationship between pitting rating and pit depth and cross-sectional area may reflect the inability of a person to distinguish very minute differences in depth that occur in smaller pits. Therefore, it was concluded that the pitting rating was a good and reliable estimate of actual pit diameter measures and that the diameter measure was most meaningful in terms of human perception.

The severity of pitting was higher in 'Bing' cherries than in 'Lapins' or 'Sweetheart' in both years (Fig. 3). Pitting ratings for 'Lapins' and 'Sweetheart' were similar in both years. Pitting ratings in all three cultivars declined with advanced maturity of harvest. This indicates that as maturity of the fruit advanced, these cultivars became less susceptible to pitting, which is parallel to earlier observations in 'Van' (Lidster et al., 1980) and 'Lambert' (Couey and Wright, 1974) sweet cherries.

Firmness declined dramatically in 'Lapins', less so in 'Bing', and not at all in 'Sweetheart' in both years (Fig. 4). Cultivar-related differences in softening have been reported previously (Choi et al., 2002a, 2002b). While fruit from all three cultivars showed parallel changes in pitting susceptibility with advancing maturity, the pattern of softening was quite different for each cultivar. Prior work has suggested that greater firmness is associated with resistance to pitting (Facteau and Rowe, 1979; Facteau, 1982), but it is clear from the current work that this is not always the case. Firmness differences at the different maturities related to pitting susceptibility in 'Bing' and 'Lapins' $\left(R^{2}=0.51, P<\right.$ 0.05 and $R^{2}=0.61, P<0.01$, respectively), however, this was not the case with 'Sweetheart' $\left(R^{2}=0.15^{\mathrm{Ns}}\right)$. Moreover, when data were combined for three cultivars, there was no significant relationship between firmness and pitting $\left(R^{2}=0.06\right.$, Ns). These results suggest that if fruit firmness is associated with pitting susceptibility, it may be only a partial determinant.

Water loss is also a potential factor in pitting susceptibility since the visual expression of the injury occurs only after water loss has been incurred by the fruit (P.M.A. Toivonen, unpublished data). This observation is supported by work showing that pitting developed faster, but not to a greater extent, at warmer storage temperatures (Lidster and Tung, 1980) where water loss is known to be much greater (Shibairo et al., 2002). The data show that weight loss decline with advancing maturity was only dramatic in 'Bing' fruit (Fig. 5) and this was associated with decline in pitting severity in that cultivar (Fig. 3). In addition, 'Lapins' and 'Sweetheart' had lower rates of weight loss along with lower susceptibility to pitting as compared with 'Bing'. However, since there was no trend between weight loss and pitting in 'Lapins' and 'Sweetheart', it cannot be concluded that weight loss is an overriding determinant of pitting susceptibility with advancing maturity in these three sweet cherry cultivars.

Changes in respiration rate (Fig. 6) were proportional to the pitting ratings (Fig. 3). Respiration rate was highest in 'Bing', intermediate in 'Lapins' and lowest in 'Sweetheart' over the different maturities of harvest and these differences were associated with the relative pitting susceptibility of these cultivars. This is similar to previous findings, which showed that cherry cultivars with greater basal respiration rates were generally more susceptible to bruising injury (Crisosto et al.,1993). However, a simple regression analysis failed to show a strong relationship between respiration rate and pitting susceptibility $\left(R^{2}\right.$ $=0.42, P<0.05$ ).

The lack of a strong or consistent relationship between each of the three physiological measures and pitting susceptibility suggested that a model containing more than one of these measures was more likely to explain differences in pitting susceptibility. Multiple regression analysis, using a model which included all three physiological measures, demonstrated that all three factors were required in the model to best explain pitting susceptibility within a cultivar (Table 1 ). However, when data for all three cultivars were used in the model, the relationship was much weaker. This finding points to the likelihood that there are other physiological determinants which were not measured in this study. For instance, prior work suggests that cell wall composition and fruit calcium status may also be important determinants of pitting susceptibility (Facteau, 1982; Lidster et al., 1979) and at least one plant growth regulator, gibberellic acid, is known to reduce susceptibility to sweet cherry pitting (Looney and Lidster, 1980).

Surface pitting in sweet cherries appears to be associated with several physiological factors. Some factors may be more important for one cultivar than another. For example, it appears that water loss in storage could be a good predictor of pitting susceptibility in 'Bing' but not in 'Lapins' or 'Sweetheart'. However, the importance of firmness and respiration cannot be ruled out in 'Bing', since the prediction is improved by adding these other factors into the model. Obviously, other factors which were not measured may also be important in determining the severity of pitting. Since there was no single measure that could be useful in predicting pitting susceptibility, the only reliable approach to assessing the potential severity of pitting in sweet cherries was the controlled application of a known force combined with a

Fig. 5. Changes in water loss during 2 weeks of storage at $1{ }^{\circ} \mathrm{C}$ for three sweet cherry cultivars with advancing maturity as determined using a CTIFL color (Centre technique interprofessionel de fruits et légumes, Paris) comparator to evaluate fruit external color. Vertical lines, when visible, represent standard errors of the means.
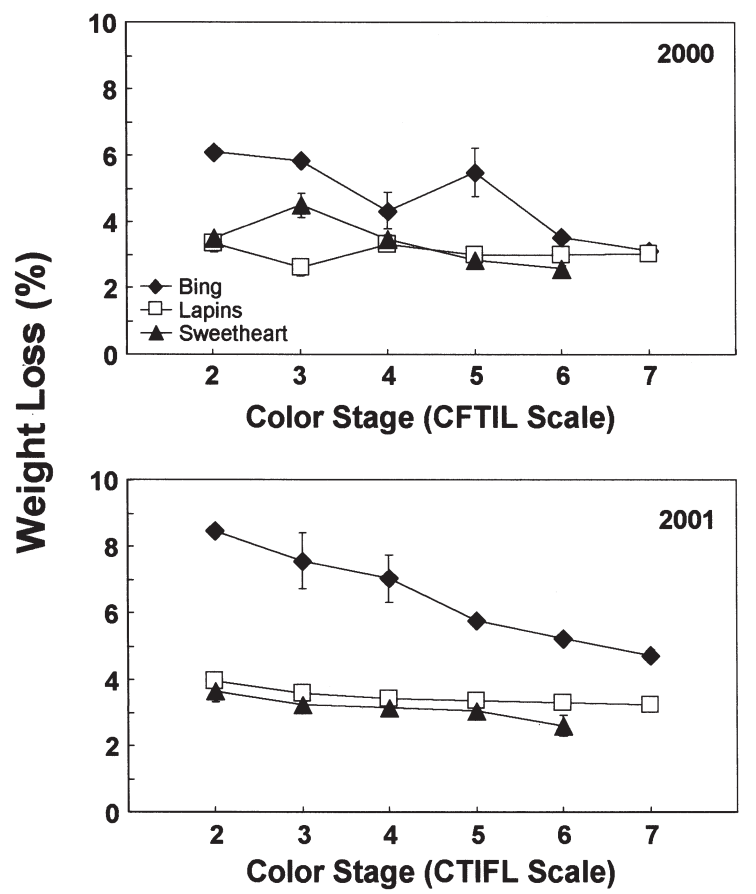


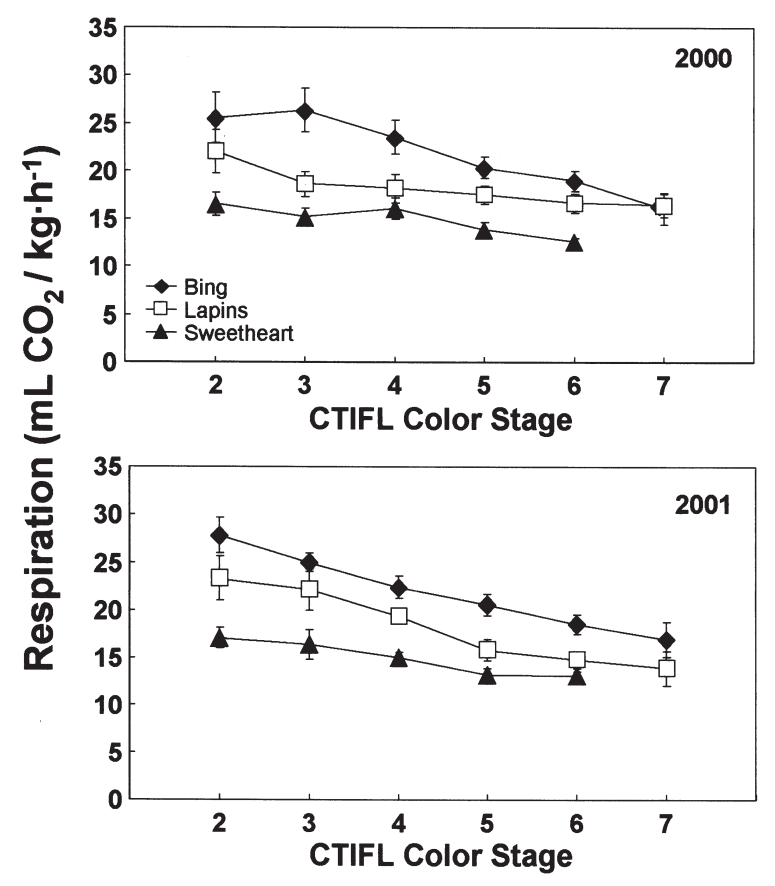

visual assessment of the injury symptom after it was given time to develop in cold storage. The results also show that the two Summerland cultivars - 'Lapins' and 'Sweetheart' - were less susceptible to pitting than 'Bing' when grown at the Summerland Research Centre site and confirm that as maturity advances in these three sweet cherry cultivars the susceptibility to surface pitting declines as it does in other cultivars.

The device and procedures developed in J. Text. Stud. 27:391-401.

Choi, C., P. Toivonen, P.A. Wiersma, and F. Kappel. 2002a. Differences in levels of pectic substances and firmness in fruit from six sweet cherry genotypes. J. Amer. Pomol. Soc. 56:197-201.

Choi, C., P.A. Wiersma, P. Toivonen, and F. Kappel. 2002b. Fruit growth, firmness and cell wall hydrolytic enzyme activity during development of sweet cherry fruit treated with gibberellic acid (GA3). J. Hort. Sci. Biotechnol. 77:615-621.

Couey, H.M. and T.R. Wright. 1974. Impact bruising of sweet cherries related to temperature and fruit

Table 1. Results of regression analysis of pitting severity against respiration rates at harvest, firmness at harvest and weight loss during 2 weeks storage at $1{ }^{\circ} \mathrm{C}$. Data from the 2000 and 2001 growing seasons were combined for these analyses.

\begin{tabular}{lcccc}
\hline Results & $\begin{array}{c}\text { Cultivars } \\
\text { combined }\end{array}$ & 'Bing' & 'Lapins' & 'Sweetheart' \\
\hline Intercept & 0.48 & 1.03 & -0.25 & -0.33 \\
Respiration & 0.06 & 0.07 & 0.02 & 0.15 \\
Firmness & 0.05 & -0.02 & 0.20 & 0.22 \\
Weight loss & 0.004 & 0.003 & 0.007 & 0.0003 \\
Adjusted $R^{2}$ & 0.63 & 0.84 & 0.85 & 0.73 \\
C(p) & 4.0 & 4.0 & 4.0 & 4.0 \\
Significance & $* *$ & $* *$ & $* *$ & $* *$ \\
Number of samples & 34 & 12 & 12 & 10 \\
\hline
\end{tabular}

\footnotetext{
${ }^{* * *}$ Significant at $P \leq 0.01$.
}

ripeness. HortScience 9:586.

Crisosto, C.H., J. Andris, K.R. Day, and D. Garner. 1994. Cold 'Brooks' cherries suffer more pitting and bruising. Calif. Agr. 48:18-19.

Crisosto, C.H., D. Garner, J. Doyle, and K.R. Day. 1993. Relationship between fruit respiration, bruising susceptibility, and temperature in sweet cherries. HortScience 28:132-135.

Facteau, T.J. 1982. Relationship of soluble solids, alcohol-insoluble solids, fruit calcium, and pectin levels to firmness and surface pitting in 'Lambert' and 'Bing' sweet cherry fruit. J. Amer. Soc. Hort. Sci. 107:151-154.

Facteau, T.J. and K.E. Rowe. 1979. Factors associated with surface pitting of sweet cherry. J.Amer. Soc. Hort Sci. 104:706-710.

Kappel, F., P. Toivonen, D.-L. McKenzie, and S. Stan. 2002. Storage characteristics of new sweet cherry cultivars. HortScience 37:139-143.

Kupferman, E., K. Miller, and B. Rengasamy. 1995. Role of temperature on reduction of cherry damage. Wash. State Tree Fruit Postharvest J. 6:14-17.

Lidster, P.D. and M.A. Tung. 1980. Effects of fruit temperatures at time of impact damage and subsequent storage temperature and duration on the development of surface disorders in sweet cherries. Can. J. Plant Sci. 60:555-559.

Lidster, P.D., K. Muller, and M.A. Tung. 1980. Effects of maturity on fruit composition and susceptibility to surface damage in sweet cherries. Can. J. Plant Sci. 60:865-871.

Lidster, P.D., M.A. Tung, and R.G. Yada. 1979. Effects of preharvest and postharvest calcium treatments on fruit calcium content and the susceptibility of 'Van' cherry to impact damage. J. Amer. Soc. Hort. Sci. 104:790-793.

Looney, N.E. and P.D. Lidster. 1980. Some growth regulator effects on fruit quality, mesocarp composition, and susceptibility to postharvest surface marking of sweet cherries. J.Amer. Soc. Hort. Sci. 105:130-134.

Patten, K.D., M.E. Patterson, and E.M. Kupferman.1983. Reducing sweet cherry surface pitting. Wash. State Univ. Publ. EB1219.

Plaxton, W.C. 1996. The organization and regulation of plant glycolysis. Annu. Rev. Plant Physiol. Plant Mol. Biol. 47:185-214.

Porritt, S.W., L.E. Lopatecki, and M. Meheriuk. 1971. Surface pitting-A storage disorder of sweet cherries. Can. J. Plant Sci. 51:409-414.

Shibairo, S.I., M.K. Upadhyaya, and P.M.A. Toivonen. 2002. Changes in water potential, osmotic potential, and tissue electrolyte leakage during mass loss in carrots stored under different conditions. Sci. Hort. 95:13-21. 